\title{
Incremento de resistencia a la compresión del concreto obtenido a través de adición de ceniza de rastrojo de maíz
}

\author{
Ing. Edson Julio Salas Fortón \\ Director del Departamento Académico de Ingeniería Civil
}

\section{INTRODUCCIÓN}

En el presente artículo, comento sobre el trabajo de investigación denominado: «Análisis comparativo de la resistencia a compresión del concreto adicionado con rastrojo de maíz elaborado con agregados de las canteras de Cúnyac y Vicho con respecto a un concreto patrón de calidad $\mathrm{f}^{\prime} \mathrm{c}=210 \mathrm{k} / \mathrm{cm}^{2} \gg$. Trabajo que sirvió también como tesis de grado en la Escuela Profesional de Ingeniería Civil de la Universidad Andina del Cusco, mediante la cual se titularon los autores, y ahora colegas: Ing. Mónica Alexandra Galicia Pérez e Ing. Marco Antonio Velásquez Curo, en el que participé como asesor de tesis.

Los antecedentes relacionados al tema de investigación, que sirven como base para el trabajo son: «Las cenizas de cáscara de arroz, adición puzolánica en cemento y concreto», realizado por la Dra. Rosaura Vásquez A. y la Bach. Patricia Vigil, de la Universidad de Piura-Perú en el año 2000 y «Estudio de morteros de cemento Pórtland con ceniza de rastrojo de maíz: posibilidad de uso en construcciones rurales», realizado por el Bach. Alejandro Escalera Cruz, de la Universidad Politécnica de Valencia-España, en el año 2008.

\section{IMPORTANCIA DEL ESTUDIO}

Desde la patente del cemento tipo Pórtland, realizada por el inglés Joseph Aspdin, en el año 1824; se han producido gran cantidad de cementos enmarcados, generalmente, entre los cinco tipos tradicionales. Al mismo tiempo, se realizaron mejoras en el proceso de producción del cemento y el concreto, las cuales han cambiado desde: variación de las composiciones químicas, temperaturas de cocción, procesos de quemado, clinkerización, finura del material, uso de aditivos, entre muchos otros. La mayoría de ellos destinados, principalmente, a mejorar la resistencia a compresión del concreto, pues es su principal característica como material de construcción. 
Una de las mejoras sustanciales a destacar, es la adición de puzolana al cemento, que consiste en incrementar cierta cantidad de sílice o sílice-alúmina, con el fin de que —en reacción con el hidróxido de calcio del cemento-, esta mezcla adquiera propiedades cementicias (proceso que se da siempre y cuando la puzolana presente 'reacción cementicia').

En el Perú, el uso de cenizas para la mejora de las características del cemento tipo Pórtland es realizado por empresas privadas, además, la investigación en el tema es reducida o poco difundida por razones de secreto de fábrica, lo cual es entendible. Existen nuevos cementos que están aportando mejores características al producto. Para el caso, la Escuela Profesional de Ingeniería Civil de la Universidad Andina del Cusco, no podía estar ajena al estudio de tan importante insumo, que viene a ser más usual en otros medios.

Es así, que se estudió la variación de la resistencia a la compresión del concreto adicionado con ceniza, el desarrollo de la resistencia a la compresión, el porcentaje óptimo de ceniza que nos permite alcanzar mayor resistencia al aplastamiento. De igual modo, se estudió otros factores anexos como la consistencia y la resistencia a flexión.

\section{METODOLOGÍA}

Se trabajó usando el método hipotético deductivo, nos apoyamos en el diseño de la investigación mediante matrices de consistencia. El diseño fue experimental, pues se manipuló la variable independiente «porcentaje de ceniza incorporada al concreto patrón»; y se observó cómo varían la «resistencia a la compresión y desarrollo de la resistencia», «porcentaje óptimo para lograr la mayor resistencia a la compresión», «consistencia» y «resistencia a la flexión».

\section{MATERIALES}

El trabajo de investigación realizado utiliza como adición a un concreto patrón de calidad $f^{\prime} c=210 \mathrm{~kg} / \mathrm{cm}^{2}$; cenizas del residuo orgánico proveniente de la quema del rastrojo de maíz proveniente de las plantas cultivadas en el distrito de Saylla, Región Cusco-Perú.

El concreto patrón es elaborado con cemento tipo IP, agregados de uso comercial en la zona provenientes de las canteras de Cúnyac y Vicho, agua de la red pública. El diseño es realizado mediante el método del ACI (American Concrete Institute). 


\section{PROCEDIMIENTO}

Un primer paso fue determinar si el material presentaba indicios de reacción cementicia, la que fue considerada positiva —al apreciar después del análisis químico del rastrojo—; mayor cantidad de sílice en su composición y, de esa manera, clasificarlo como puzolana silícea.

La secuencia de la obtención de la puzolana ha sido:

1. Recolección del material.

2. El quemado es realizado elaborando hornos artesanales con ladrillos de arcilla y mejorar el proceso de cocción mediante la incorporación de aire.

3. Luego se realiza la molienda mediante el uso de molinos caseros manuales.

4. El tamizado es realizado a través de la malla estandarizada para granulometría n. ${ }^{\circ} 50$ (ASTM).

5. Realizar un segundo quemado al material pasante seleccionado, hasta obtener un material de color plomo claro.

La evaluación se hace mediante la elaboración de un 'concreto patrón' elaborado con insumos de la zona, al cual se añadió la puzolana obtenida en los porcentajes de: 2,5 \%, $5 \%$ y $7,5 \%$ del peso del cemento.

Finalmente, se evalúan las resistencias a la compresión, de acuerdo a la NTP 339.034 (NTP: Norma Técnica Peruana), la flexión de viguetas de concreto según la NTP 339.072, la consistencia, según los parámetros de la NTP 339.035.

\section{RESULTADOS}

a.- La resistencia a la compresión es "superior en 47,48 \%" con respecto al concreto patrón evaluado a los 28 días.

b.- El "desarrollo de la resistencia es más rápido en los primeros catorce días" a mayor porcentaje de adición de ceniza. Y la tendencia de las curvas de desarrollo de la resistencia "tienden a confluir más allá de los 28 días de edad".

c.- La resistencia a la flexión evaluada a los 28 días, disminuye muy levemente de 20,99 $\mathrm{kgf} / \mathrm{cm}^{2}$ a $19,20 \mathrm{~kg} / \mathrm{cm}^{2}$. 
d.- A mayor adición, disminuye el revenimiento, volviéndose la mezcla menos manipulable.

\section{DISCUSIÓN}

a.- ¿El incremento de la resistencia a la compresión es resaltante?

Se ha utilizado, desde ya, un cemento puzolánico al cual se adicionó mayor cantidad de puzolana y «se ha incrementado la resistencia a la compresión del concreto adicionado con ceniza proveniente de la quema del rastrojo de maíz.»

Relevancia:

El resultado es considerado de importancia, puesto que mejora de manera significativa la resistencia del concreto ante su principal requerimiento que es la compresión, aspecto esencialmente pretendido en la tecnología del concreto.

b.- ¿Qué particularidades presentan las curvas de desarrollo de la resistencia a compresión?

Se aprecia mayor resistencia inicial y desarrollo rápido hasta los 14 días a mayor adición de ceniza. Luego, las curvas presentan tangentes menores.

Relevancia:

La característica de rápido desarrollo de la resistencia inicial favorece —en el caso de que se necesite desencofrado rápido - o es importante para concreto expuesto a climas fríos, su utilidad sería similar a la dada para el cemento tipo III.

c.- ¿Se determinó un porcentaje óptimo de adición al concreto, de manera que se logre la mayor resistencia a la compresión?

El incremento de la resistencia a la compresión ha sido proporcional a la adición de ceniza. Hubo dificultad de manipulación a mayor cantidad de ceniza adicionada.

Relevancia:

Debido a la dificultad del manipuleo alcanzado, con el 7,5 \% de adición de ceniza en peso con respecto al cemento, se podría considerar este valor como tope. 
d.- ¿La resistencia a la flexión varía de modo considerable?

La variación decrece levemente, para el $5 \%$ de adición de ceniza es no sustancial, pero se considera necesario ampliar los rangos de porcentajes de adición explorados.

Relevancia:

Si bien el concreto trabaja de manera primordial a compresión, se considera que no se debe desentender el estudio de la flexión; puesto que se aprecia una disminución.

e.- ¿Cómo afecta el menor revenimiento observado ante el incremento de porcentaje de adición de ceniza en el comportamiento de la mezcla?

Lo principal es que la manipulación del concreto es inversamente proporcional al incremento de ceniza de rastrojo de maíz.

Relevancia: La manipulación es un factor muy importante y, más aún, si se trata de concretos elaborados a distancia del punto de vaciado. Se considera importante el ampliar los estudios en los aspectos que podrían ser: tiempo de fraguado, realizar estudios con diferentes diseños de mezcla variando los revenimientos, aparte, también se puede ampliar y estudiar la interacción con otros aditivos (reductores de agua, plastificantes, súper plastificantes, etc.).

f.- ¿Cuál es el aporte general de la investigación?

Se trata de un trabajo de investigación relativo al estudio de nuevos materiales para la construcción, mediante el uso de materia prima propia de la región, así como los recursos y metodología mediante la cual, se logra un valor agregado al producto. Su procedimiento de obtención y tipo, incluso, podría ser susceptible de patente dentro del rubro de nuevos cementos o nuevos aditivos. Existe escaso conocimiento al respecto. El trabajo es un aporte a la innovación.

Otro aspecto a considerar, es que aporta luces para investigaciones similares o relacionadas. 


\section{BIBLIOGRAFÍA}

Askeland,Donald R.; Phulé, Pradeep P. ( 2004). Ciencia e ingeniería de los materiales. México DF: Thomson.

Bernal, J. (2009). Contrahipótesis: Ciencias de la construcción. Buenos Aires, Argentina: Nobuko.|

Escalera, Payá, Borrachero, Soriano y Monzó. (2008). Estudio de morteros de cemento portland con ceniza de rastrojo de maíz: posibilidad de uso en construcciones rurales. Valencia.

Recuperado el 22 de setiembre de 2017, de

https://es.scribd.com/document/335857187/Estudio-MOrtero-cemeto-ceniza-rastrojomaiz

Fernández Cánovas, M. (2013). Hormigón. Barcelona: GARCETA GRUPO EDITORIAL.

Hernández, F.; Fernández, C., y Baptista, P. (2016). Metodología de la investigación (6.ta ed.).

Lima: McGraw Hill Education. Recuperado el 20 de setiembre de 2017, de https://metodologiaecs.wordpress.com/2016/01/31/libro-metodologia-de-lainvestigacion-6ta-edicion-sampieri-pdf/

Jerónimo, M. S. (2013). Manual Técnico SIKA 2013. México DF: Sika Mexicana.

Kosmatka, Kerkhoff, Panarase y Tanesi. (2004). Diseño y control de mezclas de concreto. México DF: PCA.

Love, T. W. (1996). El concreto en la construcción. México DF: Trillas.

Ministerio de Vivienda, C. y. (2006). Reglamento Nacional de Edificaciones. Lima: Emp. Editora El Peruano. Recuperado el 15 de Setiembre de 2017, de http://www.urbanistasperu.org/rne/pdf/Reglamento\%20Nacional\%20de\%20Edificaciones .pdf

Pasquel Carbajal, E. (1998). Tópicos de Tecnología del Concreto. Lima: CIP.

Rivva López, E. (1992). Diseño de mezclas. Lima. Recuperado el 20 de setiembre de 2017, de https://es.scribd.com/doc/223658078/Diseno-de-Mezclas-Enrrique-Rivva-Lopez

Rivva López, E. (2002). Concreto de alta resistencia. Lima, Perú: Fondo Editorial ICG. Recuperado el 20 de setiembre de 2017, de https://es.slideshare.net/deibyrequenamarcelo/concreto-dealta-resistencia-enrique-rivva-lopeztecmateriales

Rivva López, E. (2012). Ataques al concreto. Lima: Fondo Editorial ICG.

Rivva López, E. (2014). Supervisión del concreto en obra (4.ta ed.). Lima, Perú: Fondo Editorial ICG. Recuperado el 20 de setiembre de 2017, de 
http://ingenieriafacil.blogspot.es/1471217390/supervision-del-concreto-en-obra-ingenrique-rivva-lopez/

Vásquez, R., Vigil, P. (2000). Las cenizas de cáscara de arroz, adición puzolánica en cemento y concreto. Piura: UDEP. Recuperado el 22 de setiembre de 2017, de https://es.scribd.com/doc/175634233/Cenizas-Cascara-De-Arroz

Velandia M., D.; Ramírez R., F. y Carrillo R. J. (2015). Concretos con cenizas volantes provenientes de termoeléctricas. Antioquia, Colombia: ECOE Ediciones. 